\title{
15 Rational Choice or Framing? Two Approaches to Explain the Patterns in the Fehr-Gächter-Experiments on Cooperation and Punishment in the Contribution to Public Goods
}

\begin{abstract}
The paper "Cooperation and Punishment in Public Goods Experiments" by Fehr and Gächter from 1999 was a milestone for the change of RCT from its standard versions to the adoption of elements from non-economic fields. The contribution investigates the scope of possible explanations for the observed patterns in the F\&Gexperiments by Rational Choice Theory (RCT) extended by motives of reciprocity, with the model of frame selection (MFS). Main result is that most findings can be reconstructed rather easily by both approaches - with one exception: After starting with punishment and after withdrawal of this option after 10 rounds subjects should following RCT react immediately with at least some defection, following MFS, however, with keeping a high level of cooperation, independently of motives of subjects. An independent empirical test with data also from other experiments (Hermann et al. 2008) confirmed this hypothesis: no change in cooperation, not even by egoists. Alternative RCT-explanations aiming to find cooperative equilibria for keeping cooperation unchanged by egoists could be the assumption of reputation-effects in finite iterated games. This interpretation, however, seems to be not plausible: Fehr and Gächter tried to control explicitly for reputation effects for all versions, and at least for the stranger-version no reputation effects are expected by RCT. The effect, however, appeared in both versions, and for the stranger-version of the data set by Hermann et al. even stronger than in the original experiment.
\end{abstract}

\subsection{Prologue}

There is a long history of consent with regard to basic assumptions on sociological theory and empirical research. It all started when Raub and Voss visited, apparently intentionally, various lectures and seminars across the newly founded universities in the Ruhr area. It was an extremely exciting time, in which the concept now known as 'model of sociological explanation' was developed - around the mid-seventies and thus long before the well-known Coleman's 'bathtub' became popular (see Coleman 1986;

Hartmut Esser, University of Mannheim

Ә Open Access. ( 2020 Hartmut Esser, published by De Gruyter. (c) BY-NC-ND This work is licensed under a Creative Commons Attribution-NonCommercial-NoDerivatives 4.0 International License. 
Raub and Voss 1981, 2017). From the beginning for many researchers, but certainly not for all, the Rational Choice Theory (RCT), which was either unknown or frowned upon within the field of sociology, became the center of the necessary microfoundation of sociological explanation. This included its particularly promising applications to social situations within game theory. Despite all advantages as compared to all other approaches, doubts occurred that it possibly doesn't capture all important aspects of (social) action, for example emotions, internalized norms, habits and - last not least - the 'definition of the situation' by 'significant' symbols, which then defines what has to be considered as 'rational'. Some of those who played a direct and leading role in these developments had, therefore, looked for ways to meet this incompleteness. Examples are Viktor Vanberg who considered rational choice as a respectively activated 'program' within situations (Vanberg 2002), or Siegwart Lindenberg and his to date further and further extended concept of goal framing (Lindenberg 2015). Such relapses had to appear strange to those who were happy to have finally discovered RCT and game theory as instruments, which seemed to make a serious, explaining sociology possible.

The author of this contribution had felt the same at first and in fact for a long time: not again all this drivel about culture! And then the attempts to integrate it into the framework of RCT! Was there any alternative? But there was more and more evidence indicating that RCT wouldn't possibly be the last word and that one wasn't able to cope with various anomalies by - more or less skillful - extensions of the theory. My personal re-framing started with different findings in the course of a long-term project on divorces. Here, empirical evidence had shown that - inter alia - the fact of the ritual of church wedding alone reduces dramatically the probability of a later divorce. This applied even after controlling for really all conceivable RCT hypotheses on this topic, like public commitment, religiosity, or normative climate within peer groups. Moreover, later marital crises are clearly reduced by church wedding, A parallel running qualitative panel study with detailed, intensive interviews revealed that in approximately two thirds of the cases there were virtually no variations in the 'framing' of the relationships, even if extreme stress occurred. In short: If the 'frame' of the relationships was 'matching' from the very beginning and if it was symbolically reinforced, the marriage would be considered as naturally intact, despite all occurring highs and lows, and a separation would be completely out of question.

On the basis of earlier considerations on the integration of approaches of symbolic interactionism for the 'definition of the situation', the theory of everyday behavior by Alfred Schütz, (1971) above all Herbert Simon's concept of 'bounded rationality' (1983) and Thomas S. Schelling's game theoretical contributions on focal points (1960), and the newly emerging script and schema theories as well as dual process models of cognitive social psychology, gave rise to the development of the model of frame selection (MFS). It allowed for - in the first instance theoretically - identifying causally the 'definition of the situation', which is controlled by symbols, and for specifying conditions for a rational choice to occur in a very simple way. And this all happens within the framework of an also formally specified theory and causal relations. 
Nearly nobody liked this model (at first). This is true for all kinds of cultural sociologists, who would lose their methodological dualistic autonomy, but also for adherents of RCT - including Raub and Voss. This becomes unequivocally obvious in several passages in a contribution to a 'polemic', which was published for a similar occasion like this one. One example: "First, it is not necessary to introduce so to say different 'forms of rationality' in order to explain normative action. Second, it is decisive to overcome the restriction to a parametrical concept of action and to take into account explicitly social interactions in processes of the definition of the situation." And subsequently: "The model of frame selection is not suitable for this." (Raub and Voss 2009: 188, translation H.E.). Here is another late reaction to these objections.

\subsection{Background}

The paper "Cooperation and Punishment in Public Goods Experiments" (Fehr and Gächter 1999; also cited as F\&G in the following) is not only a typical example of game-theoretical modeling and empirical testing of theoretically derived hypotheses, but it is also a milestone for the change of RCT from its orthodox and strict economic versions to the adoption of ever more elements from non-economic fields like cognitive psychology, sociology and anthropology. A 'general' theory of action for all social science sub-disciplines seems to be conceivable (cf. Fehr and Gintis 2007: 60f.; Gintis 2007: 15f.) and the process of convergence is actually in full speed (Tutić 2015: 84ff.). Main result of the experiment was that in a public good situation, where traditional RCT expects no contribution at all, subjects not only started with a contribution rate of about $50 \%$, but that with merely announcing the opportunity to punish free riders, contributions made a strong jump upwards and converged to nearly $100 \%$ in the following rounds - although punishment was expensive for punishers and should not occur for selfish rational actors.

Rational Choice Theorists and Behavioral Economists usually are convinced that an explanation of these and other deviations from traditional RCT is possible with rather minor changes in the two core elements, which drive the rational selection of actions: preferences and beliefs, and that it is not necessary (or even a bad mistake) to change the general micro-foundation of the selection of action as future oriented, strategic 'choice' itself. That means that other processes to explain action and behavior like pattern recognition, categorization and the triggering of reactionprograms by (subtle) symbolic cues in a situation as they were found in the seminal experiments by Tversky and Kahneman (1981) on the framing of decisions by different wordings for same incentives or by Liberman et al. (2004) on contributions to collective goods by labeling a situation with same incentives as 'Community' or as 'Wallstreet' Game were unnecessary. In both cases it became evident, that peculiar preferences to cooperate or to defect seemingly play no role. Irrelevance of other 
aspects than preferences and stability of preferences, however, are two of the key elements of any version of RCT. The findings give thus good reason to take up this point: Is it possible to explain the patterns in the F\&G-Experiment by means of RCT keeping the principles of utility maximization untouched? Or is it necessary to change not only assumptions about preferences, beliefs and utility functions but also the mechanism for the micro-foundation in face of such results.

The aim here is to compare the story RCT has to tell to explain the results of the F\&G-Experiments with the story of the MFS, which has been considered by many researchers as being not suitable at all to deal with social situations and the dynamics of interactions. The following describes first the structure and core results of the F\&G-experiment in its original version from 1999, gives a short overview of the core elements of RCT and MFS in comparison, tells two (short) stories to explain the crucial patterns of the findings with a summary for the fit of theoretical predictions with the findings, and presents an additional empirical test of both approaches.

\subsection{The experiment}

The peculiar aim of the F\&G-experiments was a systematic test for effects of opportunities to punish free riders in public good games. The prediction following strict orthodox RCT was that nobody would contribute and nobody would punish if punishment is costly. With a tiny bit of incomplete information cooperative equilibria are possible, but the specific patterns of the experiments hardly can be explained with egoistic motives alone. Fehr and Gächter therefore assumed "reciprocity" as an additional motive - over and above of altruism, which could explain cooperation, but not (costly) punishment, because punishment reduces the gains of altruism (see also section 6). The experiment lasted 20 rounds. It was split up after 10 rounds with one of the two opportunities to change to the other version for another 10 rounds. Subjects were informed about the contributions of the others after every round and knew that the experiment would be terminated after round 20. Experiments were varied in two different ways: Without and with punishment opportunity first and with randomly varying subjects in the single rounds (stranger condition), or with the same subjects over all 20 rounds (partner condition). The aim was to control for reputation effects and effects of the experience of a common history.

\subsection{Main findings}

Figure 15.1 shows the pattern of the two variants of the experiments (starting without punishment NoP1 and with punishment WiP1 in the first 10 rounds followed by a reversal in the following 10 rounds WiP2 and NoP2, respectively, each in the partner version). 


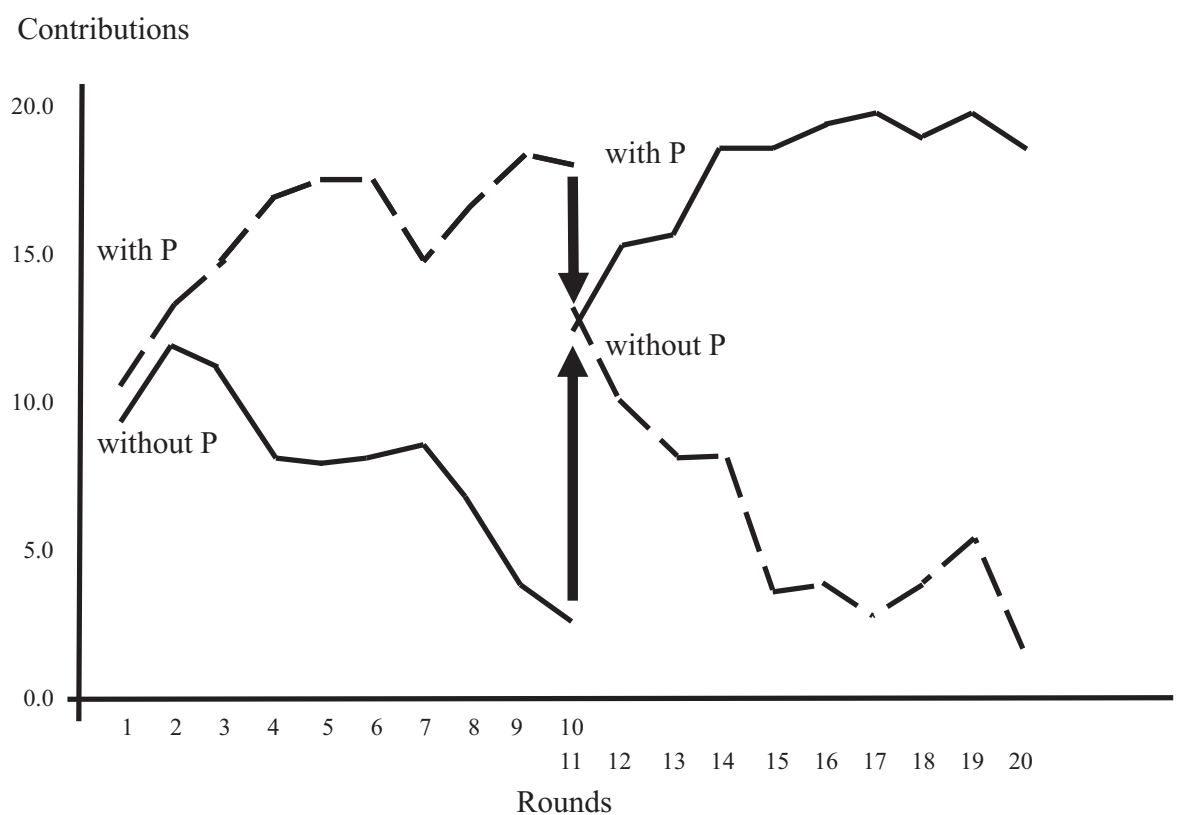

Figure 15.1: Patterns of contributions for two variants in the F\&G-experiment (partner version).

The findings can be summarized in 6 observations. ${ }^{1}$

1. With no punishment option in round 1 (NoP1) an average of about 10 units (or $50 \%$ of the maximum of 20) of contribution to the public good is observed.

2. Contributions deteriorate in the following rounds more or less steadily and approach the level of nearly overall defection in round 10.

3. With the announcement of a punishment option after round 10 (WiP2) contributions rise in round 11 immediately in a strong jump of about 10 units.

4. After round 11 with the punishment option a steady increase of contributions takes place up to about 19 of possible 20 units.

5. The general shape of the patterns is similar for both variants of order: convergence of cooperation up to nearly $100 \%$ and decay with WiP down to nearly full defection with NoP.

6. If punishment comes first (WiP1), a rather small decrease of about 4 units (from about 18 down to about 14) takes place from round 11 with no punishment (NoP2) in contrast to the jump up of 10 units up if punishment comes after no punishment (WiP2) and the decay in cooperation (from ca. 3 up to ca. 13).

1 For an extended and more detailed comparison on 14 findings see: Esser 2018: 19f. 
These six findings make up the core of the following comparison of RCT and MFS in being able to explain the patterns. The comparison refers to differences between RCT and MFS in their theoretical arguments and their ability to offer explanations without changing basic assumptions.

\subsection{RCT and MFS}

Before we start with the comparison we summarize shortly the peculiarities of RCT and MFS as background for their theoretical predictions for the outcomes in the F\&G-experiment (cf. for a summary of central RCT-assumptions: Gintis 2007, part 4; of main elements of MFS: Esser and Kroneberg 2015; and for a comparison of basic tenets of both approaches Tutić 2015, parts 2 and 3). One reason is that at least the peculiarities of MFS cannot be presupposed for most readers, in- and outside the RCT-camp, but also to demonstrate, where the substantial differences become obvious. Aspects are the basic principles to explain (re-)actions, the modeling of social situations, the explanation of processes and changes in view of each approach. Especially it should become clear, that the MFS cannot be interpreted simply as another extension of RCT - as some representatives of (orthodox and wide) RCT as well as most critics from Interpretative Paradigm or cultural sociology are inclined to do.

Two elements can be assigned as basic principle of RCT. First, action is conceived as 'choice' between alternatives by maximizing the product of preferences and beliefs for consequences in the future. Second, choices have to fulfil certain axiomatic conditions like transitivity and independence of variations in their verbal presentation. Situational cues should, therefore, have no systematic effect on preferences, but possibly on beliefs. RCT varies in some variants between fully informed homo oeconomicus with transitive preferences and differing variants of 'bounded' rationality. The respective type of rationality, however, is assumed as fixed and not subject to situational change. Emotions are not part of common versions of RCT, but are sometimes conceived of as special kind of preferences. All effects of incentives, costs or risks are conditional: They add to expected gains or losses, but without changing the respective utility functions. Social situations are characterized in RCT by common knowledge about opportunities, beliefs, and preferences of others in a situation and by anticipation of their possible reactions. The main aim of RCT is the derivation of typical equilibria for collective outcomes, in particular by instruments of game theory. Processes of strategic interaction are conceived as iterations and causally connected chains of single acts. Changes in behavior and collective outcomes are possible by two mechanisms: first, anticipation of reactions and gains/losses for a complete sequence and, second, adaptation of beliefs from the observable behavior of others by (Bayesian) learning, for instance as "conditional" 
cooperation or defection. Preferences are assumed to be stable over all situations, but can change in the long run by adaptive reinforcement-learning and evolution.

Basic principle of MFS is a process of decoding 'significant' symbols ('cues') in a situation, which trigger the activation of a specific mental model for the "definition" of the situation, the 'frame', connected programs for reacting, more or less habitualized 'scripts' for sequences of behavior and single acts. Mental models and reaction programs were encoded in the past mainly by socialization, but in part also by biological evolution. They contain typical patterns of main goals, preferences, beliefs and emotions for typical situations. The set of mental models for different situations makes up the (multiple) identity of actors. The strength of the activation for a specific frame depends on the mental model's internal accessibility, the external presence of a particular physical object, the cognitive link between mental model and physical object, and the degree of occasional noise for this link. If the match between object, cue and a (strongly) accessible mental model is perfect, the activation of a frame and the execution of the connected behavior will follow immediately and without any 'choice' and deliberation of consequences in the future. The MFS denotes it as asmode of selection. Main implication of a strong framing is the suppression of the effects of other incentives, costs, and risks with corresponding changes of the respective utility function up to the complete unconditionality of a frame. In case of a certain mis-match and strong motives and available opportunities to deliberate consequences, a 'rational' choice can take place - up to a level even orthodox RCT and homo oeconomicus presumes. MFS denotes it as rc-mode of selection. Insofar RCT could be regarded as a special case of the MFS, but with an explicit consideration of a peculiar 'definition' of the situation preceding any 'choice' - what is missing in all versions of common RCT. Social situations can be conceived in two ways in the MFS. First, as framing of the situation by mental models for types of common actions and collective outcomes. If framing is strong, a kind of mechanical coordination by the automatic activation of the same frame of social action for all actors will simultaneously take place. Second, if framing is weak and motives and opportunities for deliberating consequences are given, strategic social action will become possible - just in the same way as RCT and game theory conceive social situations - but again with a preceding definition of the type of social situation. Processes can be modelled as sequences of single acts of framing and subsequent behavior with effects on the next steps of framing and (re-) action, possibly also with switches between automatic and strategic (re-) actions in an as- or a rc-mode. Changes in framing situations (and in the modes of selection) can occur by two mechanisms. First, alterations in decoding and categorization, e.g. by sudden mis-matches and/or the appearance of cues indicating another type of situation. Second, changes in encoding mental models by adaptive learning from deviations with regard to content, accessibility and the link, which transforms objects in 'significant' symbols. For both changes actions of others can serve as cues for the framing of the situation in the next rounds. 
Table 15.1 summarizes the core constructs, proposed mechanisms and additional assumptions for both RCT and MFS (as-mode only).

Table 15.1: Basic constructs and assumptions of RCT and MFS.

\begin{tabular}{|c|c|c|}
\hline Aspects & $\mathrm{RCT}$ & MFS \\
\hline Mechanism & $\begin{array}{l}\text { Choice } \\
\text { max. expected utility } \\
\text { shadow of the future }\end{array}$ & $\begin{array}{l}\text { Categorization } \\
\text { (Mis-)Match } \\
\text { shadow of the past }\end{array}$ \\
\hline Opportunities & yes & yes \\
\hline Beliefs & yes & yes \\
\hline Preferences & yes & yes \\
\hline Emotions & (no) & yes \\
\hline Cues/Symbols & $\begin{array}{l}\text { 'cheap talk' } \\
\text { relevant for beliefs only }\end{array}$ & $\begin{array}{l}\text { 'definition of the situation' } \\
\text { relevant for beliefs and preferences }\end{array}$ \\
\hline Types of rationality & fixed & variable \\
\hline Unconditionality & no & yes \\
\hline Social situations & strategic interaction & mechanical coordination \\
\hline Processes & Sequences of situations and actions & Sequences of situations and actions \\
\hline Changes: short-term & $\begin{array}{l}\text { Bayesian learning } \\
\text { Beliefs only }\end{array}$ & $\begin{array}{l}\text { (Mis-)Match/Re-Framing } \\
\text { Beliefs and preferences }\end{array}$ \\
\hline long-term & $\begin{array}{l}\text { adaptive reinforcement } \\
\text { evolution }\end{array}$ & $\begin{array}{l}\text { adaptive reinforcement } \\
\text { evolution }\end{array}$ \\
\hline
\end{tabular}

\subsection{Two (Short) stories}

RCT-explanations of the empirical patterns of the findings in the F\&G-Experiment (Figure 15.1) start with the assumption of social motives as preferences and two types of actors: egoists (EP) and altruists (AP). In WiP1 both types start with their preferences: EP-types defect, AP-types cooperate. The sharp decay of cooperation after a certain period of stability can be explained by 'conditional cooperation': Altruists learn, that they are exploited and that it is better to defect, simply as defense. With the announcement of the punishment opportunity Altruists have an offensive option: to punish defectors. Cooperators with only altruistic motives, however, would not choose this option, because any punishment is not only costly, but decreases their own benefits, like the feeling of a warm glow by cooperation itself and for the well-being of others. In order to explain the rise of contributions after the decay in round 11, 
additional motives have to be assumed: Cooperators are not only altruistic, but 'reciprocals' (RP) with strong motives to retaliate against defections. EP-types know this, anticipate severe punishment and cooperate, because this pays now for them. RPtypes anticipate this and start for WiP2 with the punishment option in round 11 with cooperation - on a higher level not only after the decay before, but also in comparison to the beginning in NoP1. The steady rise of contributions after round 11 up to nearly $100 \%$ can thus be explained easily: Both EP- and RP-types have good reasons to continue with cooperation - even if not all participate immediately, but quickly learn that cooperation is better for them, too.

The MFS-explanation of the pattern starts also with a distinction of motives, but not as stable characteristics of actors over different situations, but as varying imperatives in situations. The no punishment situation in the F\&G-Experiment is objectively one of the type of a prisoner's dilemma, but not framed very clearly. If we assume some kind of default options for not clearly defined situations, Cicourel's 'basic rules of interactions', results for round 1 can be explained by following their mental models of $\mathrm{EF}$ or $\mathrm{AF}$ : 50\% cooperation, 50\% defection in each case. If reactions in the first round (and later) serve as cues to define the situation more clearly, the decay in cooperation can be explained as stepwise increase of a framing as Wallstreet Game, where selfishness and competition prevail, until all actors follow this definition of the situation regardless of their social motives. The announcement of punishment after round 10 serves in a similar way as significant cue for another definition of the situation: not as Community Game with rather innocent altruism and friendliness, but as 'Reciprocity' Game, connected with strong inclinations to retaliate against defections immediately and without any consideration of further consequences as the costs of punishment. This not only explains the higher level of contributions in round 11 as compared with the undefined situation in round 1 with its random or default reactions, but also the sudden jump of about 50\% difference up from the level after the decay of cooperation before. The steady rise up to nearly full cooperation in the last round would be a consequence of the increasing match for the reciprocation frame - backed by effectively punishing defectors and collecting more and more collective gain - up to the end of the last round.

\subsection{Comparison}

Table 15.2 provides an overview of the theoretical arguments and assumptions of the two approaches to explain the six findings mentioned above.

For findings 1 to 5 both approaches can rather easily explain the respective patterns (with different theoretical arguments). The base is a peculiarity of reciprocity: Common knowledge of the possibility of self-inflicting retaliations by (strong) emotions is presumed by RCT for the assumption of a subgame perfect equilibrium 
Table 15.2: Theoretical arguments and assumptions to explain the F\&G-findings. ${ }^{2}$

\begin{tabular}{lll}
\hline Findings & RCT & MFS \\
\hline 1 & Types of preferences (EP, AP) & Types of frames (EF, AF) \\
\hline 2 & conditional cooperation: beliefs C/D & Mis-Match AF \\
\hline 4 & common knowledge P with WiP2 & activation RF with WiP2 \\
\hline 5 & common knowledge P with WiP2 & increasing match for RF \\
\hline 6 & similar conditions in both versions & similar conditions in both versions \\
\hline
\end{tabular}

given the punishment option, instant activation of strong affects and inclinations to retaliate against violations of cooperation- and fairness-norms as part of the reciprocity frame activated by the announcement of the punishment option is presumed by the MFS. Finding 6 indicates, however, a difference. RCT predicts a clear decrease in contributions after removing the punishment option as first sequence: Selfish defectors now have not longer to fear retaliations, and altruistic cooperators are facing the risk to be exploited. MFS in contrast assumes a process of strengthening accessibility and match of the reciprocation frame first with a following history of high, stable and unbroken cooperation: An increased 'priming' of AF by repeated cooperation of nearly all. Defection after removing the punishment options could, therefore, be perceived as occasional mis-match of a firmly established frame in which cooperation prevails. This explains the rather small decay of contributions with the change from punishment to no punishment - in contrast to the reversed situation of the decay of cooperation first, increasing anger of exploited cooperators, who will change immediately to reciprocation if punishment becomes possible. Finding 6, however, confirms MFS, but RCT has no explanation for the asymmetry in changes of contributions between round 10 and 11 for the two variants of NoP1 and WiP1 (highlighted in Table 15.3).

The summary in Table 15.3 refers to the most extended variant of wide RCT so far: from the orthodox version with the assumption of selfish motives only (RCT 1.0) over the extension by motives of conditional cooperation, warm glow, altruism, fairness or inequity aversion (RCT 2.0) to the assumption of another type: strong reciprocation with a nearly unconditional willingness to punish violations of group standards (RCT 3.0). Table 15.3 summarizes how the different versions of RCT fit with the 6 findings (numbers indicate confirmation of the resp. finding).

2 Preferences: Egoism (EP), Altruism (AP), Reciprocity (RP); Frames: Egoism (EF), Altruism (RP), Reciprocity (RP); (Re-)Actions: Cooperation (C), Defection (D), Punishment (P). 
Table 15.3: Theoretical predictions and empirical fit between variants of RCT and MFS.

\begin{tabular}{|c|c|c|c|c|c|c|}
\hline \multirow[b]{3}{*}{ F. } & \multirow[b]{3}{*}{ Content } & \multicolumn{5}{|c|}{ theoretical predictions and empirical fit } \\
\hline & & \multicolumn{3}{|c|}{ RCT } & \multicolumn{2}{|c|}{ MFS } \\
\hline & & RCT 1.0 & RCT 2.0 & RCT 3.0 & PBB & $\mathrm{RCT}^{*}$ \\
\hline 1 & $50 \%$ C rd. 1 for NoP1 & refuted & 1 & 1 & 1 & (1) \\
\hline 2 & $15 \%$ C rd. 10 for NoP1 & 2 & 2 & 2 & 2 & (2) \\
\hline 3 & $65 \%$ C rd. 11 for WiP2 & refuted & refuted & 3 & 3 & (3) \\
\hline 4 & $95 \%$ C rd. 20 for WiP2 & refuted & refuted & 4 & 4 & (4) \\
\hline 5 & same both versions & 5 & 5 & 5 & 5 & $(5)$ \\
\hline 6 & asymmetric change rd. 11 & not expl. & not expl. & not expl. & 6 & (not expl.) \\
\hline
\end{tabular}

RCT 1.0 is clearly refuted by most of the findings. Only two of the six findings are in accordance with selfish utility maximization in public goods games: decay of cooperation as consequence of attempts to defend oneself against further exploitation (finding 2), independently of the order of both sequences (finding 5). The assumption of altruism as social motive in RCT 2.0 allows an explanation of even high rates of cooperation in the first rounds of the sequences (finding 1) and for the larger effects for partners (finding 9): Motives for cooperation compensate probably the selfish ones, and for cooperation with partners higher amounts of warm glue and stronger beliefs in the reliability of their type may arise. To explain the effects of the punishment option, however, more than social motives of warm glow or altruism has to be assumed: credible willingness to strongly and unconditionally retaliate against defective deviations from a group standard (RCT 3.0). With one exception, all findings can be explained with these assumptions. The exception concerns the rather small decrease of cooperation after punishment: Defectors don't change their identity even by long sequences of successful cooperation before in round 11 for WiP1 to NoP2, and they should reduce their contributions immediately just by the same amount, by which they increased their contributions with announcement of the punishment option in round 11 for NoP1 to WiP2.

The listed arguments of MFS in Table 15.2 refer to the as-mode of an automatic activation of a certain kind of what Victor Vanberg sometimes has called program based behavior (PBB). All 6 findings fit with the MFS-predictions for this case. MFS, however, comprises also 'rational choice' as selection-mechanism - provided that conditions for the rc-mode are met and, thus, in principle for all versions of RCT as special cases (including the applicability of all formalizations and instruments like game theory). But this does not mean a straightforward subsuming of common RCT simply under the rc-mode of the MFS: For the MFS, all selections are preceded by a 
process of categorization and a certain 'definition' of a situation, and it depends on the strength and content of framing, what happens. The strength of framing determines the degree of (variable) rationality and the content how a situation is seen and 'interpreted' by actors. Framing, then, can be a matter of automatic activation as well as of a 'rational choice'. This implies that any 'definition' of a situation will lose its unconditionality, if cues are ambiguous and accessibility for a specific mental model is weak. In this case other motives can interfere, like especially selfishness, which always tends to be pushed to the fore and to override social motives and the impulse for costly emotional reactions (according to Goal Framing Theory by Lindenberg 2015: 47ff.). This specific MFS-version of RCT with framing is labeled as $\mathrm{RCT}^{\star}$ - in remembrance of the concept of 'unit act' proposed by Talcott Parsons already in 1937, who postulated that any act is preceded by a 'normative orientation', which defines the situation with respect to preferences, beliefs and perceived opportunities. The MFS is the formalized version of this concept, enriched and completed by well-established insights and findings from cognitive psychology, neuroscience, anthropology and evolutionary biology since this contribution of Talcott Parsons to a 'General Theory of Action'.

For the F\&G-Experiment RCT* would make in principle the same predictions as version RCT 3.0 (with the same arguments, assumptions, confirmations, refutations, and blanks in explanations). But RCT 3.0 assumes a preceding step of 'definition' of the situation with effects like those in the experiments by Tversky and Kahneman or Liberman et al. That leads to another MFS-story - now for framing the situation in the $r c$-mode. Beginning again with no punishment first and assuming a rather open, undefined situation (as in the F\&G-experiment) selfish or social preferences and types of actors determine what happens: More than 50\% cooperation from the beginning, conditional cooperation and decay. Assuming a clear cue for cooperation- or reciprocity-frame contributions should change: an even higher cooperation rate and no decay. Wallstreet-cues would have the reverse effect: suppression of cooperation and no change for the following (as in the Libermanexperiment). For all effects and patterns possible framing-effects, however, would be weaker in case of a rc-mode as compared to an as-activation: A certain mismatch is one of the necessary conditions for any (rational) deliberation. And referring once more to Lindenberg's Goal-Framing Theory, selfish motives should become stronger with the degree of (possible) deliberation. Exactly that is observed accidently and mostly more as by-catch in other experiments of behavioral economics (Costa et al. 2014; Duwfenberg et al. 2011; Ellingsen et al. 2012; Engel and Rand 2014; Rand et al. 2012; Rubinstein 2013). In Table 15.3 predictions and fits with the 6 findings are, therefore, presented in brackets for version RCT* - 'Rational Choice' in the rc-mode of the MFS. 


\subsection{A separate test}

The only case where the approaches contradict each other theoretically is finding number 6 with the asymmetry occurring when the punishment option is changed between round 10 and 11. This relates directly to the core of both approaches: According to RCT, same reactions should occur both upwards and downwards, regardless of whether the punishment option is introduced or abolished in the first or second sequence. The only thing that counts is the common knowledge of the options, and neither introducing or abolishing the punishment option leads to changes in preferences. By contrast, according to the MFS on would expect different reactions (in the as-mode): Introducing the punishment option after prior decay of cooperation without punishment option (transition NoP1 to WiP2) will result in a significant jump upwards, too. Abolishing the punishment option after having started with it and after the subsequent sequence with high cooperation rates (transition WiP1 to NoP2), however, will (at least in the first instance) will cause no special change. The theoretical argument for this refers to the basic mechanism of frame selection: the increasing match of a cooperation (resp. reciprocity) frame via a process of an ever stronger activation of the framing, being reinforced by cooperative acts themselves, the iterative symbolic 'constitution' of a cooperation 'community', just as it had been observed in Liberman's experiments in the 'community game' or analogous field experiments on priming of altruistic attitudes (cf., inter alia, Keizer et al. 2013).

So much on the reconstruction of the findings that can be reconstructed from the publication of the F\&G experiments. But would there also be a chance for a test independently of the published results? An obvious way is linked to the core of the respective approaches: actors' preferences (EP and RP) and the different frames (EF and RF). It is possible to derive specific hypotheses from both approaches with regard to changes in the transition from round 10 to round 11 for both versions (NoP1WiP2 and WiP1-NoP2).

RCT suggests that introducing or abolishing the punishment option alone will change the respective expectations: Accordingly, changes would amount to the same effect on cooperation for both types in both directions (see the left-hand side of Figure 15.2: RCT, NoP1-WiP2 and WiP1-NoP2 for EF and RF). The main reason is that following RCT beliefs only would change, but preferences should remain constant. If beliefs on other's cooperation are increased, however, temptations to defect after the withdrawal of the punishment-option would be even higher than before and rather strong defection should follow in round 11. In contrast, according to MFS one would expect a differential pattern (see the right-hand side of Figure 15.2: MFS, NoP1WiP2 and WiP1-NoP2 for EF and RF). This is because changes vary with the content of framing (EF and AF type) and with the accessibility of respective cues, here the announcement that a punishment option is introduced or abolished. Four theoretical expectations result from this: First, in version NoP1-WiP2 there is a clear change 


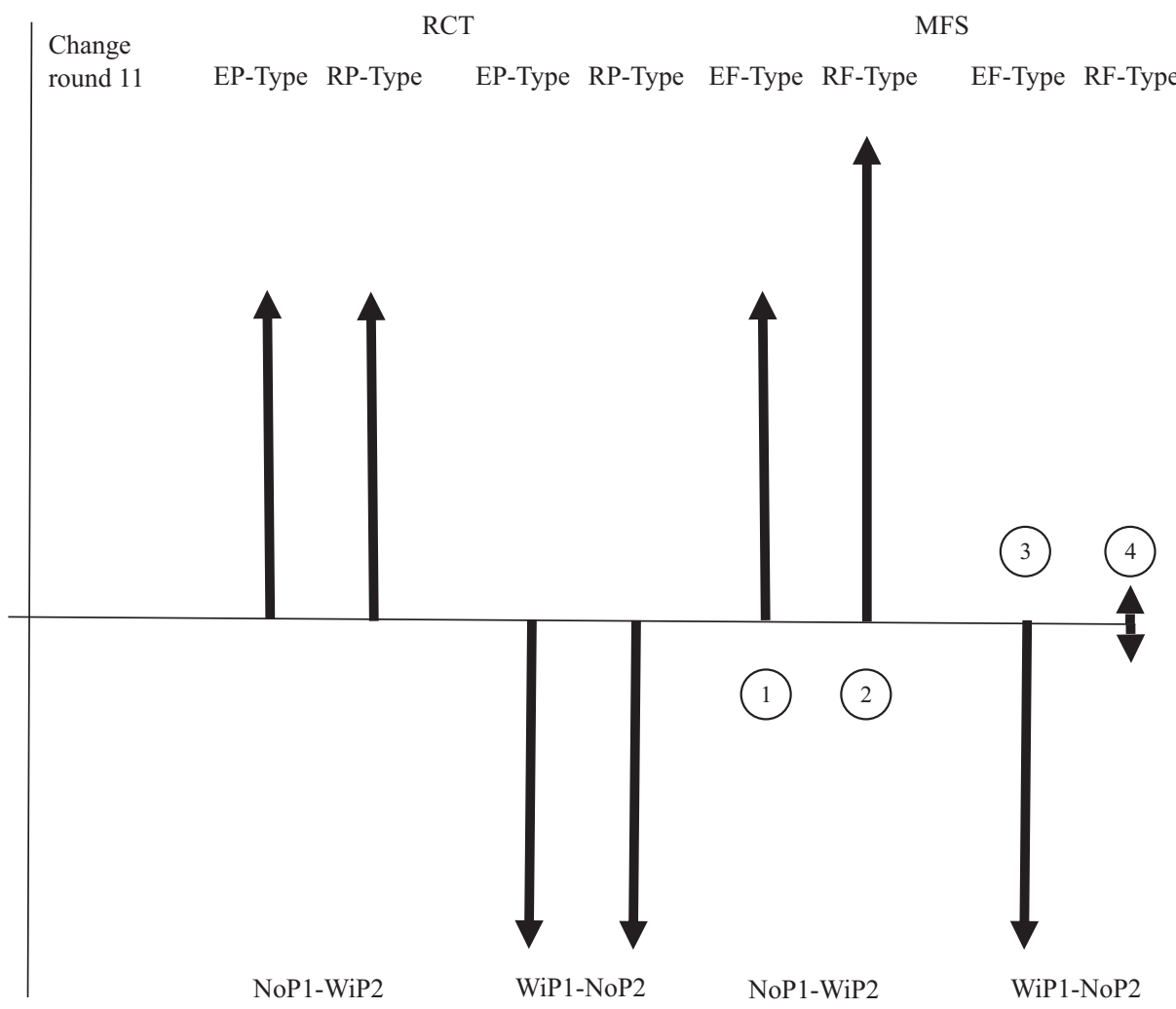

Figure 15.2: Theoretical expectations of RCT and MFS regarding the effects of introducing or abolishing the punishment option between rounds 10 and 11 of both versions NoP1-WiP2 and WiP1NoP2 according to actors' preferences and frames (EP/EF type and RP/RF type; cf the text above on the different numbers).

upwards for EF types after introducing the punishment option after round 10, quite similar to the magnitude of the change as proposed by RCT (for all types), because their expectations change (Figure 15.2, number 1). Second, among RF types cooperation increases clearly, too, in version NoP1-WiP2 in round 11. However, it exceeds the changes among EF types (and all of RCT), because the reciprocity frame is (only) available for RF types (Figure 15.2, number 2). Third, in version WiP1-NoP2, contributions immediately decline among EF types after a long period of high cooperation between rounds 2 and 10: What counts for them (as for RCT in general) are only expectations, and if the risk for punishment no longer exists, they will have no reason for cooperation anymore. In addition, there is no 'community' priming, because it is not available to them (Figure 15.2, number 3). Fourth, according to the MFS, nearly no changes will finally occur among RF types in the transition WiP1-NoP2, at least not in round 11 (Figure 15.2, number 4): Among them, the RF frame is ever further activated 
through mutual cooperation. Only more obvious and repeated disruptions of the prior 'constitution' of the cooperation 'community' may finally give rise to conditional defection in subsequent rounds.

Three specific hypotheses on the relationships of differences in contributions between rounds 10 and 11 result from this. First, the difference in the change of cooperation between rounds 11 to 12 as regards version NoP1-WiP2 is significantly positive for $\mathrm{RF}$ types as compared to EF types (compare number 1 with number 2). Second, between versions NoP1-WiP2 and WiP1-NoP2 there is no difference with regard to the amount (!) of the change among EF types: Their contributions decrease to the same extent when the punishment option is abolished as it increased before its introduction (compare the amount of number 1 and 3). Third, among RF types no change in cooperation occurs in the transition for version WiP1-NoP2 in round 11 as compared to round 10 (number 4).

How could one make an empirical comparison if the types weren't measured separately? One simple consideration provides the solution: The behavior in question when options change, relates to what happens in rounds 10 and 11, but prior sequences exist and one can presume at least for round 1 that actors followed (largely) their (private) motives and mental models. These reactions can, therefore, be used as (proxy) measurements of the types, analyses can be conducted separately for both types, and the findings can be compared with the hypotheses stated in Figure 15.2. This is exactly what had been done then.

As the number of cases in the original experiment (Fehr and Gächter 1999 - for Zürich) appeared to be too small for separate analyses, another dataset which is comparable with the approach was used and pooled. ${ }^{3}$ The types were dichotomized according to their contributions in the respective first round. All subjects who had spent at least half of their available means (10 out of 20 units) were classified as RF types and those who had spent less than one half as EF types, respectively. This corresponds to a central theoretical aspect in the explanation of reciprocity effects: Already simple fairness norms include sharing as being part of the basic rules of interaction and only those who stay below can be designated as egoist. This creates a certain asymmetry in the distribution of the types, because there aren't so many

3 The dataset used by Hermann et al. (2008) includes altogether 17 cities from different national cultures. Except the one for St. Gallen, none of the experiments there corresponds to the approach of the original experiment in F\&G 1999, because either they considered only one version of introducing the punishment option, or they conducted fewer rounds (for example, six rounds twice instead of 10 rounds twice). Anyway, St. Gallen would have proven more suitable for an analysis, because with it the wider national-cultural context was held constant. Zürich was also included in the complete dataset, but it's structure didn't correspond with the one in the F\&G experiment, too. Different from the original experiment, however, only a stranger version of the experiment was conducted, which normally shows the whole pattern less pronounced (cf. the findings 13 and 14 on partner versions in Fehr and Gächter 1999). This makes the test conducted here even more thorough as compared to the hypotheses of the MFS. 
egoists then, particularly when the game starts with an available punishment option (WiP1-NoP2). This cannot be avoided, but testing for 'significant' effects is thus conducted even more thoroughly.

The findings of the analyses testing the three hypotheses are summarized in Table 15.4 .

Table 15.4: Changes in contributions at the transition from introducing or abolishing the punishment option between rounds 10 and 11 from NoP1 to WiP2 and from WiP1 to NoP2 for egoists and altruists (EF and RF types) using the pooled dataset (Fehr and Gächter 1999 for Zürich; Hermann et al. 2008 for St. Gallen); bold: difference significant with $p \leq 0.001$.

\begin{tabular}{|c|c|c|c|c|c|c|c|c|c|c|}
\hline \multirow[b]{3}{*}{ Version } & \multicolumn{3}{|c|}{ Average Contribution } & \multicolumn{6}{|c|}{$\begin{array}{l}\text { Hypotheses MFS (H) } \\
\text { and findings F\&G (B) }\end{array}$} & \multirow[t]{3}{*}{$r$} \\
\hline & \multirow{2}{*}{$\begin{array}{r}a \\
\begin{array}{r}\text { Round } \\
10\end{array}\end{array}$} & \multirow{2}{*}{$\begin{array}{r}\text { Round } \\
11\end{array}$} & \multirow{2}{*}{$\begin{array}{r}\mathrm{c} \\
\text { Diff. } \\
11-10\end{array}$} & \multicolumn{2}{|c|}{1} & \multicolumn{2}{|c|}{2} & \multicolumn{2}{|c|}{3} & \\
\hline & & & & H & B & H & B & H & B & \\
\hline NoP1-WiP2 & 3.4 & 12.3 & 8.9 & plus & 4.2 & & & & & 25 \\
\hline $\begin{array}{l}\text { EF Type } \\
\text { RF Type }\end{array}$ & 2.4 & 15.5 & 13.1 & & & & & & & 47 \\
\hline WiP1-NoP2 & 8.9 & 8.5 & -0.4 & & & zero & -8.5 & zero & 1.4 & 13 \\
\hline $\begin{array}{l}\text { EF Type } \\
\text { RF Type }\end{array}$ & 15.6 & 17.0 & 1.4. & & & & & & & 51 \\
\hline
\end{tabular}

The first hypothesis is clearly confirmed (column 1): The difference in contributions between rounds 10 and 11 (columns a and b) among RF types exceeds by 4.2 units significantly the one among EF types (column c). In contrast, the second hypothesis of the MFS proves to be incorrect, at least at first sight (column 2). It is expected that the amount of change among EF types between rounds 10 and 11 remains the same for both versions, NoP1-WiP2 and WiP1-NoP2, and thus, this difference equals zero (column 2H). Yet, the change during transition to WiP1-NoP2 amounts only to -0.4 (column c WiP1-NoP2, EF type), so that the difference with regard to the change in version NoP1-WiP2 is smaller by 8.5 units that the reference value of the change of 8.9 units for the transition regarding NoP1-WiP2 (column c, NoP1-WiP2, EF type). To put it more simple: Contrary to hypothesis 2 of the MFS, EF types virtually don't respond to the abolishment of the punishment option in round 11 after a long period of prior cooperation. The third hypothesis is then again confirmed clearly (column 3): With regard to version WiP1-NoP2, RF types continue their high levels of cooperation, which indeed even further increase by 1.4 units: from 15.6 units in round 10 to 17.0 units in round 11 (column c, WiP1-NoP2, AF type). The findings are summarized graphically in Figure 15.3. 


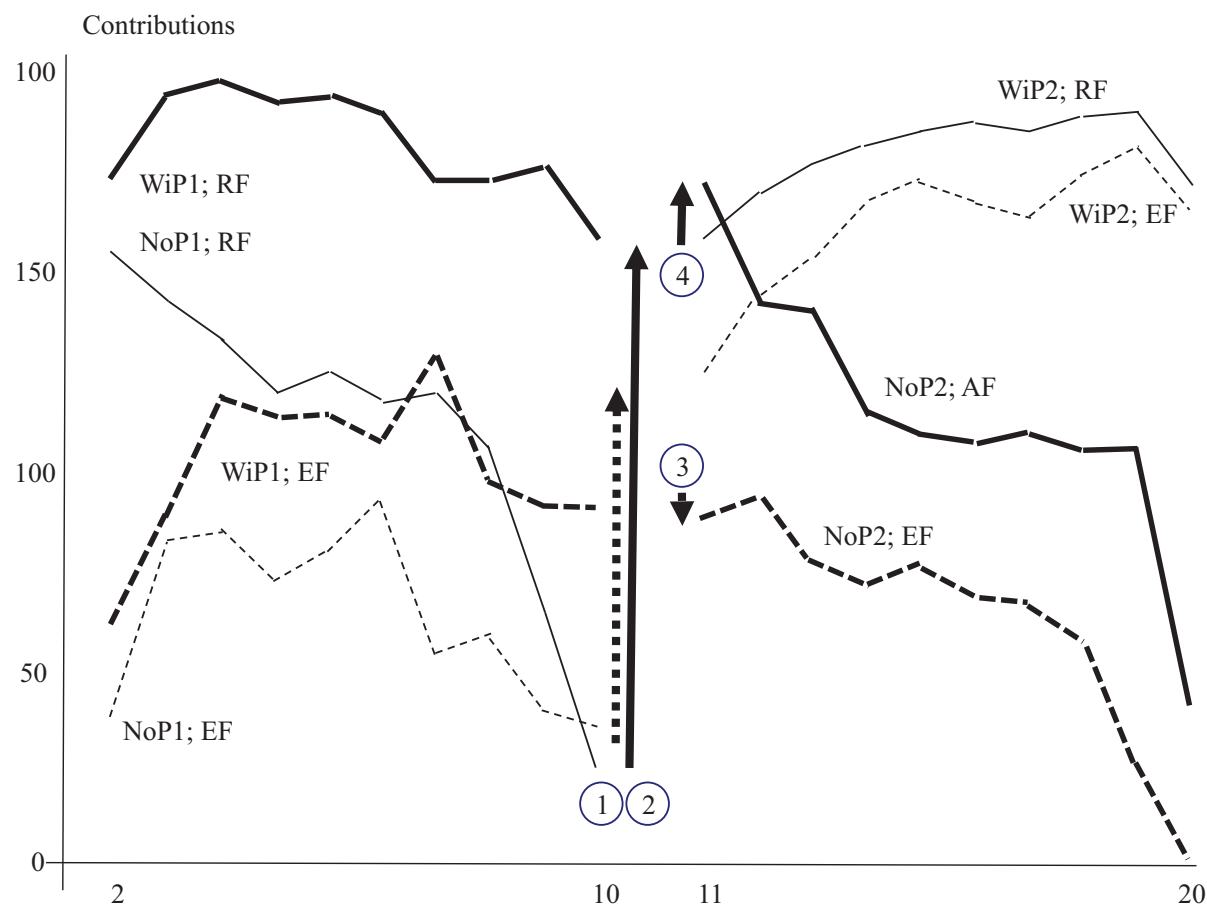

Figure 15.3: Cooperation in the F\&G-experiment for the two versions NoP1-WiP2 (thicker lines) and WiP1-NoP2 (thinner lines) in dependence on actors' frames (EF types: dashed lines, RF types: solid lines; cf. the text on arrows and numbers; without round 1, which was used to determine the different types).

The according to hypothesis 2 greater decline in cooperation among EF types (Table 15.4, column 2) looks like a refutation of the MFS. But is this really true? Hypothesis 2 is based on the really extreme assumption that egoists are basically not susceptible to a cooperation priming over long sequences of a profitable community. This seems not to be true and there is considerable ethnographic evidence in support of this. Already the various experiments by Liberman had demonstrated that the 'definition' of a game's framing can override all preferences. Although differences in the level of cooperation between EF and RF types remain in phase WiP1, the decline in round 11 with NoP2 predicted by RCT (3.0) doesn't occur. Despite all egoism there obviously always exists also a certain susceptibility to processes of symbolic constitution of a cooperation community and a mitigation of reactions to changes in opportunity structures and incentives alone. In any case this finding is a clear rejection of RCT, even in its widest version: namely the assumption that 'framing' and 'definition of the situation' don't exist and that symbols and language are nothing but 'cheap talk'. 


\subsection{Evaluation}

Reconstruction of the F\&G-experiments with RCT and MFS shows, that both approaches work rather well. But both have also to make several assumptions without a really sound theoretical and/or empirical foundation until now.

The main problem for RCT is the stepwise extension of types of motives and actors, sometimes appearing simply as post-hoc-'explanation' of clear refutations of the foregoing version of RCT by assuming a new motive for what had just been observed: selfishness, altruism, strong reciprocity, the last including the assumption of the activation of emotions for explaining costly retaliations and thus transcending the boundaries of core elements of common RCT again. It looks sometimes very much like a degenerative problem shift. Two of the six findings could not be explained even by version RCT 3.0 with reciprocity as a stable trait of types of actors, and especially the absence of end-game-effects in the very last round after high cooperation contradicts each of the three versions of RCT.

The MFS is able to explain these two anomalies of RCT 3.0 rather easily if conditions for the as-mode were met: A longer period of cooperation strengthens at least a Cooperation-frame, and single interferences, e.g. by announcement that the punishment option is withdrawn now, are not able to re-frame the situation instantly. The same should apply for end-game-effects if punishment is possible and high cooperation prevails in the second sequence. And: Emotions are not a strange addendum for MFS, but an essential part of any program based behavior (PBB) in an as-mode of framing, activated in an uncontrollable way by certain 'significant' symbols or cues. Indirect evidence for framing-effects, including the activation of emotions and unconditional retaliation of defections, which serve as (very) significant cues triggering aggressive reaction in a Reciprocity-frame, is given by Fehr and Gächter themselves (see above). For $\mathrm{RCT}^{*}$ and rc-condition predictions and preceding framing are somewhat different to those of common RCT without any assumption of preceding framing: The 'rational' choices hinge at least partly also on a 'rational' selection of a specific frame, but the effects are weaker in its strength and more selfish in content - the less strong a situation is defined and the more opportunities to deliberate are available. Predictions and fits for $\mathrm{RCT}^{*}$ are therefore also marked by brackets in Table 15.3 .

The detailed analysis of the F\&G-Experiment leaves the question quite open, whether RCT delivers a satisfying explanation within its (more and more opened) boundaries or whether MFS fares better. Both approaches have at least one problem in common: Any additional assumption decreases the logical content of a theory, and that applies to RCT as well as to MFS. RCT has to extend types of motives and actor - up to the assumption of unconditional emotions, and MFS has to distinguish and verify types of frames and certain conditions for the mode-selection. Because both approaches differ strongly in core constructs and assumed mechanisms they can hardly be compared in their logical content. But such an incommensurability is 
inevitable in most cases of 'correcting' explanations and theory development. It is the price for achieving a 'comprehensive', general theory, which explains the anomalies of different approaches by preserving its merits.

F\&G-experiments have speeded up undoubtedly the process of a kind of unification of social sciences by employing some changes in types of preferences in the initial conditions of RCT, but Liberman-experiments and occasional findings of framing effects in behavioral economics remind that this could perhaps not be enough. MFS is a conjecture to integrate framing-effects into a comprehensive concept of a 'general' theory of action - even if a majority of cases can be explained actually by means of (wide) RCT alone. But a rigorous experimental test is still missing. What could be done, however, as a first next step seems to be obvious: combining the F\&G-experiments with the Liberman-experiments and varying the easiest possibility to restrict opportunities for deliberation, namely time pressure to react in situations defined by different cues for frames with different types of actors.

\subsection{Epilogue}

Many have always viewed the MFS with skepticism. And there have been periods, partly up to date, when differences seemed to increase and when mutual rationalizations of the superiority of one's own approach have started to prevail once more (see Fehr and Gintis 2007: 60f., Gintis 2017: 161ff., Chapter 12). There are certainly good reasons for such resistances, as we know from Lakatos' work: As long as one has an alternative useful theory: formally precise, logical in substance, empirically proven, one won't change it only because single anomalies occur. This even applies in case that anomalies increase in number - as long as no better alternative is in sight and as long as one can hope that the problems can be solved by (more or less: marginal) changes in the established approach. And this is exactly what has been done for a long time: extension of RCT by introducing ever more additional motives and, finally, the withdrawal to a purely formal definition of RCT by, for example, certain axioms. But the rather flat waves of a slowly upcoming flood of hardly adjustable anomalies also from game theoretical experiments take their toll on even core assumptions of RCT. In addition, it is obvious that prominent representatives, who are well aware of all RCT's possibilities, themselves attempt to solve these problems (cf. Tutic 2015 on the approach of an integrative microfoundation from various convergences regarding developments within economy, cognitive (social) psychology, and sociology). It looks as though these developments have meanwhile also influenced some criticasters, at least there are indications that they have in the meantime been acknowledged as noteworthy developments in the microfoundation of the model of sociological explanation (Raub and Voss 2017: $29 \mathrm{f}$.). Not everybody has this open-mindedness and self-confidence to admit, that there is perhaps more 
that has been established by now. I wish to thank Werner Raub especially, who, unlike others, was willing to do so.

\section{References}

Coleman, James S. 1986. "Social Theory, Social Research, and a Theory of Action." American Journal of Sociology 91:1309-1335.

Costa, Albert, Alice Foucart, Sayuri Hayakawa, Melina Aparici, Jose Apesteguia, Joy Heafner, and Boaz Keysar. 2014. "Your Morals Depend on Language." PLoS ONE 9(4), e94842. doi: 10.1371/ journal.pone.0094842.

Diekmann, Andreas, and Thomas Voss. 2008. Die Bedeutung „sozialer“ Motive für die RationalChoice-Erklärung sozialer Normen. Pp. 83-7100 in: Andreas Diekmann, Klaus Eichner, P. Schmidt, and Thomas Voss (eds.), Rational Choice: Theoretische Analysen und empirische Resultate. Festschrift für Karl-Dieter Opp zum 70. Geburtstag. Wiesbaden: VS Verlag für Sozialwissenschaften.

Dufwenberg, Martin, Simon Gächter, and Heike Hennig-Schmidt. 2011. "The Framing of Games and the Psychology of Play." Games and Economic Behavior 73(2):459-748.

Ellingsen, Tore, Magnus Johannesson, Johanna Mollerstrom, and Sara Munkhammar. 2012. "Social Framing Effects: Preferences or Beliefs?" Games and Economic Behavior 76(1):117-130.

Engel, Christoph, and David G. Rand. 2014. "What Does 'Clean' Really Mean? The Implicit Framing of Decontextualized Experiments." Economics Letters 122(3):386-389.

Esser, Hartmut. 2017. "When Predictions Fail. Reactions of Rational Choice Theory and Behavioral Economics to the Unexpected Appearance of Framing Effects." Pp. 505-75026 in: Ben Jann, and Wojtek Przepiorka (eds.), Social Dilemmas, Institutions and the Evolution of Cooperation. Berlin and Boston: De Gruyter/Oldenbourg.

Esser, Hartmut. 2018. Sanktionen, „Reziprozität und die symbolische Konstruktion einer Sanktions-'Gemeinschaft'. Ein theoretischer Vergleich und empirischer Test von RationalChoice-Theorie und dem Modell der Frame-Selektion anhand von Befunden und Daten aus der experimentellen Spieltheorie zur Erklärung der Bereitstellung von Kollektivgütern." Zeitschrift für Soziologie 37: 8-28.

Esser, Hartmut, and Clemens Kroneberg 2015. "An Integrative Theory of Action: The Model of Frame Selection." Pp. 63-85 in Edward J. Lawler, Shane R. Thye, and Jeongkoo Yoon (eds.), Order on the Edge of Chaos. Social Psychology and the Problem of Social Order. Cambridge: Cambridge University Press.

Fehr, Ernst, and Simon Gächter. 1999. Cooperation in Public Goods Experiments. Working Paper No. 10. Institute for Empirical Research in Economics. University of Zürich.

Fehr, Ernst, and Herbert Gintis. 2007. "Human Motivation and Social Cooperation: Experimental and Analytical Foundations." Annual Review of Sociology 33:43-64.

Gintis, Herbert. 2007. "A Framework for the Unification of the Behavioral Sciences." Behavioral and Brain Sciences 30:1-61.

Gintis, Herbert. 2017. Individuality and Entanglement. The Moral and Material Basis of Social Life, Princeton NJ und Woodstock. Oxfordshire: Princeton University Press.

Hermann, Benedikt, Christian Thöni, and Simon Gächter. 2008. "Antisocial Punishment Across Societies." Science 319: 1362-1367.

Keizer, Kees, Siegwart Lindenberg, and Linda Steg. 2013. "The Importance of Demonstratively Restoring Order.” PLOS ONE 8(6). e65137, doi:10.1371/journal. pone.0065137. 
Liberman, Varda, Steven M. Samuels, and Lee Ross. 2004. "The Name of the Game: Predictive Power of Reputations versus Situational Labels in Determining Prisoner's Dilemma Game Moves." Personality and Social Psychology Bulletin 30(9):1175-1185.

Lindenberg, Siegwart. 2015. "Social Rationality and Weak Solidarity. A Coevolutionary Approach to Social Order." Pp. 43-62 in Edward J. Lawler, Shane R. Thye, and Jeongkoo Yoon (eds.), Order on the Edge of Chaos. Social Psychology and the Problem of Social Order. Cambridge: Cambridge University Press.

Rand, David G., Joshua D. Greene, and Martin A. Nowak. 2012. "Spontaneous Giving and Calculated Greed." Nature 489:427-30.

Raub, Werner. and Thomas Voss. 1981. Individuelles Handeln und gesellschaftliche Folgen, Darmstadt: Luchterhand. Soziologische Texte, Neue Folge, Band 120.

Raub, Werner, and Thomas Voss. 2009: “Lob des Modellbaus.” Pp. 167-198 in Paul Hill, Frank Kalter, Johannes Kopp, Clemens Kroneberg, and Rainer Schnell (eds.), Hartmut Essers Erklärende Soziologie. Kontroversen und Perspektiven. Frankfurt and New York: Campus Verlag.

Raub, Werner, and Thomas Voss. 2017: "Micro-Macro-Models in Sociology: Antecendents of Coleman's Diagram.” Pp. 11-36 in Ben Jann, and Wojtek Przepiorka (eds.), Social Dilemmas, Institutions and the Evolution of Cooperation. Festschrift for Andreas Diekmann. Berlin and Boston: De Gruyter/Oldenbourg.

Rubinstein, Ariel. 2013. “Response Time and Decision Making. An Experimental Study.” Judgement and Decision Making 8(5):540-551.

Schelling, Thomas S. 1960. The Strategy of Conflict. Cambridge, MA: Cambridge University Press.

Schütz, Alfred. 1971. „Das Wählen zwischen Handlungsentwürfen.“ Pp. 22-69 in Alfred Schütz, Gesammelte Aufsätze, Band 2: Studien zur soziologischen Theorie, Den Haag: Martinus Nijhoff.

Simon, Herbert A. 1983. Reasons in Human Affairs. Stanford, CA: Stanford University Press.

Tutić, Andreas. 2015. "Warum denn eigentlich nicht? Zur Axiomatisierung soziologischer Handlungstheorie." Zeitschrift für Soziologie 44(2):83-98.

Tversky, Amos, and Daniel Kahneman. 1981. "The Framing of Decisions and the Psychology of Choice." Science, New Series 211( 4481):453-458.

Vanberg, Viktor J. 2002. "Rational Choice vs. Program-Based Behavior: Alternative Theoretical Approaches and their Relevance for the Study of Institutions." Rationality and Society 14: 7-54. 
